Revista Iberoamericana, Vol. LXXIII, Núm. 221, Octubre-Diciembre 2007, 871-886

MOBILIS IN MOBILI: CIENCIA Y TECNOLOGÍA EN EL ETERNAUTA

\author{
POR \\ Claudio Canaparo \\ Centre for Latin American Studies \\ University of Exeter
}

La eternidad EDITORIAL de El Eternauta

Héctor Germán Oesterheld (1919-circa 1977) realizó los primeros borradores del guión de la historieta Una cita con el futuro: El Eternauta, memorias de un navegante del porvenir entre 1955 y 1956, la cual fue publicada por primera vez, con dibujos de Francisco Solano López (1928- ), en el suplemento semanal de la revista Hora Cero Semanal a partir de septiembre de 1957. La saga de El Eternauta puede ser establecida o a partir de quienes fueron sus dibujantes (indicadas como "versiones”) o a partir de un ordenamiento de acuerdo con la trama (indicadas como "partes”). En el primer caso habría seis períodos: (i) la versión realizada por Francisco Solano López (1957-1959); (ii) la versión realizada por Alberto Breccia (1919-1993) para la revista Gente en 1969; (iii) otra versión de Solano López aparecida en la revista Scorpio entre 1976 y 1978; (iv) la versión italiana también realizada por Solano López y editada en la revista LancioStory entre 1977 y 1978; (v) las versiones en las que no participa ya H. G. Oesterheld, aparecidas a partir de 1981; y, finalmente, (vi) la versión novelada de El Eternatura editada en forma póstuma como libro por Ediciones Colihue en 1996. ${ }^{1}$

En cuanto al ordenamiento a partir de la trama, El Eternatura puede ser divido en tres grandes partes: (i) la versión original (“primera parte”) que es la editada a partir de 1957

\footnotetext{
${ }^{1}$ La historieta aparecía primero en la página 7 del número 1 de dicho suplemento semanal, el 4 de septiembre y a un precio 1,50 pesos de la época. La revista aparecía con tapa a dos colores, dieciséis páginas, se imprimía de forma apaisada y aparecía los miércoles. La "tira” se publicaba a razón de tres o cinco planchas por ejemplar y se prolongó hasta el 9 de septiembre de 1959, en la página 19 del suplemento número 106 (Morhain). En 2004 la colección completa de esta versión original fue editada como libro. A esta versión en adelante la indicaremos como EEO (“El Eternauta original”). La segunda versión adquirió reputación no sólo por los dibujos vanguardistas y provocativos de Breccia sino también porque fue abruptamente interrumpida. La misma fue editada entre los números 201 y 217 de Gente. En 1996 la colección completa de esta versión original fue editada como libro. A esta versión en adelante la indicaremos como EEG (“El Eternauta Gente”). En 2004 la colección completa de la tercera versión original fue editada como libro. A esta versión en adelante la indicaremos como EES (“El Eternauta Skorpio”). La versión italiana, por cuestiones de adaptación gráfica y traducción, presenta varias modificaciones respecto del original. En adelante a esta versión la indicaremos como EEL (“El Eternauta LancioStory”). A la versión novelística la indicaremos como EEN (“El Eternauta Novela”).
} 
y que incluye la versión aparecida en la revista Gente y unos números sueltos aparecidos en 1958, 1962-1963 y 1965; (ii) la “segunda parte” que es la aparecida bajo Ediciones Record a partir de 1976; y (iii) la "tercera parte” también editada por Ediciones Record, con guión de Alberto Ongaro y dibujos de Mario Morhain y Oswal, cuyo original fue editado por primera vez en Italia en 1983. El resto de episodios sueltos o incompletos se acoplan a alguna de estas tres versiones. A los propósitos de este escrito hemos elegido trabajar con las diecisiete entregas en que consistió la versión de El Eternauta aparecida en la revista Gente (EEG) en 1969. ${ }^{3}$ Sin embargo, también utilizaremos las dos versiones más importantes (EEO y EES) y la novela (EEN) como apoyo de los argumentos y cuando sea posible ya que las diferencias entre versiones pueden ser notables.

\section{LA HISTORIETA DE LA HISTORIETA}

Como no es propósito de este escrito dilucidar la situación lingüística y/o sociológica de la historieta, el mismo parte de la asunción de que El Eternauta constituye un objeto cultural que conjuga texto e imágenes -a partir de una narración-y que puede ser enfocado desde dos perspectivas diversas: a partir de una semiología centrada en la historieta en sí como objeto/producto cultural, siguiendo, por ejemplo, las ideas de Fontanille o Floch, o a partir de un análisis que además explora el paratexto y un sistema de signos y objetos en el cual la historieta se situaría, tomando en cuenta por ejemplo el trabajo de Genette, Bourdieu y Baudrillard. ¿Hasta qué punto es posible llevar adelante una exploración de la primera perspectiva sin involucrarse en la segunda? Por supuesto que semejante exploración es imposible desde el punto historiográfico y epistémico. ${ }^{4} \mathrm{Y}$ por ello es necesario establecer claramente que este escrito es un análisis parcial y limitado de $E l$ Eternauta, dedicado a un aspecto en particular, y como tal debe entenderse. ${ }^{5}$ Por otra parte, es relevante mencionar que en la actualidad El Eternauta ya no circula como historieta sino como libro o como academic subject. ${ }^{6}$ Ello no sólo permite realizar ciertas conjeturas

\footnotetext{
${ }^{2}$ De los números sueltos tenemos: El Eternauta. Episodio unitario, aparecido como suplemento en Hora Cero Extra 1 (1958) con dibujos de Solano López; El Eternauta. Los episodios novelados, aparecido en la revista Eternauta 4-15 (1962-1963) con dibujos de varios artistas; y Muerte. La precuela de El Eternauta, aparecido en la revista Geminis 2 (1958) con dibujos de Alberto Breccia. ${ }^{3}$ Las entregas fueron realizadas entre el 29 de mayo y el 18 de septiembre de 1969. La elección se asienta en razones estéticas, de argumentación y de límites en la extensión del presente escrito. Véase por ejemplo Morhain (66).

${ }^{4}$ Para una concepción práctica, clara y funcional de la historieta, referida en particular a El Eternauta y al contexto rioplatense, puede consultarse Morhain (37-55). Para una perspectiva más genérica, también pueden verse Masotta; De Santis; Rivera; Trillo y Saccomanno.

${ }^{5}$ Para una visión panorámica de la obra y de la biografía de H. G. Oesterheld puede consultarse el film documental $H G O$.

${ }^{6}$ Véase por ejemplo Gociol y Rosemberg; y también Sasturain. Es necesario puntualizar que en cuanto a su formato existen dos períodos en El Eternauta. El que podemos indicar como "primer período" de las tres partes conocidas y, un "segundo período”, que abarcaría las diversas reediciones de estas partes. Si en el primero la edición se hace en forma de revista y por entregas, por el contrario, en el segundo predomina la idea de "libro” o de “colección” y las entregas son en su mayoría de tipo
} 
acerca de los procesos culturales, sino también poner en cuestionamiento no pocas hipótesis acerca de la función de la historieta y su relación con los medios de comunicación y el conjunto de sistemas simbólicos que todavía algunos entienden como sociedad.

Contrariamente a lo que se postula,Apocalittici e integrati no inaugura la legitimización del análisis académico de la historieta. ${ }^{7}$ Lo que sucede es que una nueva disciplina -la semiología (Barthes), la semiótica (Eco)- cuestiona las perspectivas sobre las cuales los análisis culturales habían sido llevados a cabo hasta entonces. Lo que tiene una doble consecuencia: obviamente que manifestaciones como la historieta serán consideradas con mayor equidad y relevancia (los análisis semióticos desdeñan conceptualmente por lo general las perspectivas “cultura alta/cultura baja”), pero también que los contenidos y formas de las narraciones que sostienen la historieta no pueden ser entendidos como lo era hasta entonces la literatura, de cuyo modelo se extraía por lo general aquello que se entendía como "crítica cultural”. Las ideas de "modernidad”, “identidad cultural”, "dependencia cultural”, "género menor”, "cultura popular”, ${ }^{8}$ entre otras, asociadas a la historieta, constituyen por ejemplo uno de estos resultados en donde la perspectiva epistemológica empleada para analizar la historieta hace que la misma aparezca considerada como literatura llevada adelante por otros términos o medios.

En Kafka: pour une littérature mineure y en Critique et clinique Gilles Deleuze y Felix Guattari analizan esta cuestión de la "literaturización” de los análisis y plantean algunas de sus consecuencias epistémicas más relevantes (1993). Bajo estas condiciones, el saber filosófico y/o conocimiento es considerado como un fenómeno escrito o, más concretamente, como una dimensión narrativa; de allí que, bajo estas condiciones, confundir "literatura" con narración constituiría un infortunio epistemológico. ${ }^{9}$ Por otra parte, aquello que podríamos indicar provisoriamente como realismo, como iluminismo y como cientificismo son los aspectos -ya considerados entre las consecuencias estimadas por Deleuze y Guattari- a destacar en el caso particular que nos ocupa. Por razones de espacio nos ocuparemos aquí sólo del tercer aspecto. ${ }^{10}$

\section{La Cientificidad de la CienCia Ficción}

La confusión entre ciencia y tecnología se debe sobre todo a que se transfieren los atributos de la técnica a la tecnología, por ello se acaba entendiendo la tecnología como

unitario o vinculadas a sistemas de distribución ajenos a la historieta. En ambos casos, sin embargo, resulta interesante constatar que la distribución se realiza en su mayoría a través de "kioscos".

${ }^{7}$ Véase por ejemplo la perspectiva de Foster; y también puede consultarse Morhain (45).

${ }^{8}$ Véanse por ejemplo Foster; Gociol y Rosemberg; Sasturain.

${ }^{9}$ Ello se vincula, como decimos, al hecho de que, cuando los analistas o autores de historietas se ocupan de Oesterheld, en particular cuando se trata de situarlo en una suerte de evolución cultural, más aún, de la historia intelectual o de las mentalidades, piensan en términos literarios y no con una epistemología adecuada al hecho, por ejemplo, de que El Eternauta circula en un mundo contemporáneo donde ni "sociedad" ni "cultura" son conceptos que signifiquen ya gran cosa. Ideas peregrinas como las de "héroe colectivo" o "planteo tercerista” (Sasturain 112 y 124) son el resultado de esta concepción decimonónica de literatura aplicada de modo genérico al análisis de una cultura. ${ }^{10}$ Sobre las ideas de "realismo" e "iluminismo" relacionadas al tema presente puede consultarse Canaparo Ciencia 561-893 y 897-1079. 
sinónimo de "saber", es decir, como ciencia en sentido puro. ${ }^{11}$ Sobre esta confusión se ha construido la idea de un "género" de "ciencia ficción”. La apelación a lo Real se halla en la base de la "ciencia ficción”. Por ello es que es relevante evaluar la relación entre ciencia y tecnología en términos conceptuales y no necesariamente ignorarlos bajo el pretexto de que, en definitiva, “ciencia ficción” es una narración de ficción (Goimard 15). El cine asimismo ha largamente difundido y canonizado esta perspectiva de “ciencia ficción” cuyo original proviene de la literatura y de los comics- donde se confunde ciencia con tecnología y tecnología con saber; el ejemplo probablemente más notorio tal vez sea el filme Doctor Frankenstein. Desde sus orígenes las así llamadas narraciones de ciencia ficción, más que de “ciencia”, se ocupaban de difusión científica (“ciencia popular”) y de los alcances y dimensiones sociales de la difusión y empleo de la tecnología. La ciencia aplicada no existe puesto que toda ciencia, todo saber indicado como científico, es siempre "aplicado". ${ }^{12}$ Aquello que en innumerables ocasiones se ha indicado como "ciencia aplicada” es en realidad tecnología; la gran diferencia estriba en que, en la actualidad, la tecnología ha crecido a unas proporciones que eran impensables en el siglo xix, cuando las primeras firmes manifestaciones de narraciones de ciencia ficción fueron establecidas en sentido moderno. ${ }^{13}$

Volviendo sobre la demarcación inicial, podríamos decir que en sentido moderno la técnica ( $\tau \varepsilon \chi v \eta$, ars mechanica) constituye un conocimiento funcional, específico, determinado y abstracto, mientras que la tecnología ( $\tau \varepsilon \chi v o \lambda o \gamma o \varsigma$, sistema artificial) constituiría menos un saber que una manera de producir, de fabricar o de emplear aparatos u objetos de índole física; uno no "sabe” por la tecnología ni por la información que ella puede generar o contener sino por el empleo de la misma. La tecnología no es un aparato o instrumento sino un sistema, sin embargo, la difusión científica durante el siglo xx, al igual que los relatos de ciencia ficción, como veremos, han alentado la idea de que la identificación o posesión de un aparato o instrumento puede ser asociado con "tecnología”. La técnica es el método de construir artificios físicos mientras que la tecnología es el sistema de aparatos y objetos en sí, hayan sido ellos derivados de una técnica o no. Sin embargo, la producción artificial a gran escala que domina nuestra contemporaneidad hace que la distinción entre técnica y tecnología sea cada día menos factible, ${ }^{14}$ y de allí la

\footnotetext{
${ }^{11}$ Para un análisis de la noción de "técnica" desde una perspectiva filosófica puede consultarse Ortega y Gasset; en particular puede verse el capítulo "Meditación de la técnica”. También puede verse Habermas.

${ }^{12}$ Véase Glasersfeld. En una conversación entre Salvo y Franco puede leerse: “¿Cómo hiciste para salvarte? ¿Estabas con alguien que conocía la física?” (Salvo) “No... estaba yo solo y yo solo me hice el traje. Usted sabe, yo leo mucho... Novelas, historietas del futuro, de ficción científica...” (Franco) (EEO 103).

${ }^{13}$ Es indudable que existe una relación directa entre las primeras publicaciones de difusión científica y la creación de un género de ciencia ficción, por cuanto la noción de ciencia en ambas áreas coincidía en más de una ocasión. Sobre la idea de ciencia y la difusión científica en el siglo xix puede consultarse Cantor y Shuttelworth; y también Cantor et al.

${ }^{14}$ Véase por ejemplo Ortega y Gasset. Por la misma razón es que la mayoría de los autores que se ocupaban de la relación problemática entre ciencia y tecnología han abandonado también la cuestión conceptual referida a la técnica. Véase por ejemplo Jasanoff.
} 
perdurabiliad del nombre "ciencia ficción” cuando en realidad deberíamos hablar de "ficción tecnológica”.

La ciencia ( $\varepsilon \pi 1 \sigma \tau \eta \mu \eta$, episteme) por otra parte, constituye un entendimiento escrito, una serie de cuestiones historiográficas, epistemológicas y, en muchas ocasiones, editoriales; es un saber en el sentido de $\pi$ oınбıৎ (poiesis). La ciencia también puede ser entendida como el método para construir artificios imaginarios e invisibles. De allí que, en el ámbito de la ciencia ficción, sea tan común la confusión entre la ya mencionada definición de técnica y esta acepción de ciencia. La idea de mundos artificiales gobierna casi toda la historia y evolución de aquello que indicamos como ciencia ficción precisamente por esta misma razón: la fascinación que produce la idea de "inventar" cosas que no existen, de viajar hacia lo desconocido ("inimaginable”) con la mente y la tecnología, constituyen elementos que han caracterizado la idea de ciencia hallable en las narraciones de ciencia ficción.

La confusión entre ciencia y tecnología consiste entonces en que se toma la tecnología como ciencia de manera tal que los atributos creativos de la ciencia son trasladados a los posibles resultados que pueden obtenerse de los aparatos o instrumentos considerados como sinónimos de tecnología. Esta confusión entre un saber especulativo y una práctica instrumental atraviesa todo el género llamado ciencia ficción (Muñoz 12), y a partir de ella pueden sin duda conjeturarse las razones de gran parte de su popularidad y éxito comercial. En este contexto es entonces donde es interesante situar a El Eternauta como una historieta que describe elementos de tecnología pero intenta presentarlos como componentes de un "saber". De esta manera la actividad científica se convierte en algo omnicomprensivo ya que incluye los aparatos e instrumentos, el sistema que forman y el "saber" que los justifica o sitúa en sentido evolutivo.

En El Eternauta la ciencia es entendida como aquello que hace posible lo que el presente aún no es: "platos voladores", "viajes en el tiempo", "nieve que mata”, etc. La ciencia es también el arma más eficaz contra lo imprevisible y contra lo desconocido. Por otra parte, todo enfrentamiento -real o imaginario-, toda dificultad a resolver, todo problema inmediato, es constantemente medido en términos de tecnología. A esta mezcla entonces de ciencia y tecnología la indicaremos como ciencia-tecnología y la misma constituye el verdadero realm sobre el que se asienta todo principio de entendimiento o realidad en la "ciencia ficción” de El Eternauta. Y como para que no queden sitios para la especulación acerca de esta situación, la trama presenta al “enemigo” como una especie de agente atmosférico del cual nadie puede escapar (EEG 91).

El carácter de ciencia ficción de El Eternauta está también dado por las constantes especulaciones acerca de “mundos”, viajes, viajeros, interacción entre hombres y máquinas, evaporación del tiempo y la regular necesidad de situarse espacialmente que poseen los protagonistas: “...Estoy en la tierra supongo” (EEG 84). En este sentido es interesante destacar que todos los artefactos y aparatos presentados en la historieta “como de ficción”, en realidad ya constituyen objetos de uso corriente en la actualidad, excepción hecha de la máquina de viajar en el tiempo y las diversas formas de robots que aparecen (EEG 130). De esta manera, El Eternauta es en la actualidad menos una narración de "ficción tecnológica” -posibilidad de existencia de aparatos o instrumentos que no aún existen- 
que de "ciencia ficción" -posibilidad de entender o saber aquello que constituye un problema-, por cuanto el centro de gravedad de su argumento se halla en la idea de viaje y en la noción de conocimiento y/o relación del mismo con el presente. Y es por esto último que El Eternauta (EEO y EEG) nos parece interesante. Porque, aún con sus limitaciones, El Eternauta (EEO y EEG) no trata de sacar partido de la confusión entre ciencia y tecnología sino que considera a la misma como un estado de las cosas y la mente.

FAVALLI, EL LABORATORIO Y LA CIENCIA-TECNOLOGÍA

La cientificidad de la llamada "ciencia ficción”, al menos en el sentido con que aparece en relación con El Eternauta, se asemeja a un cientificismo, a una versión de la ciencia y la tecnología basada en parámetros de difusión científica característicos de los medios de comunicación del siglo xx. ${ }^{15}$ Bajo estas condiciones, en el centro de gravedad de dicho cientificismo se halla el laboratorio como el lugar de origen de esta cienciatecnología. Por ello El Eternauta comienza allí, en el “laboratorio” de Salvo (EEG 85). El laboratorio es un lugar recóndito, poco accesible y donde se llevan adelante actividades de invención o de destreza técnica. ${ }^{16}$ El laboratorio sirve para afrontar lo desconocido, para fabricar cosas, para crear herramientas y armas de defensa, y funciona también como "refugio"; sea para jugar al truco como para protegerse de los extraterrestres, "El ‘laboratorio’ tiene de todo” (EEG 93). El laboratorio confirma el carácter tecnológico de la actividad científica tal como es entendida en la historieta y la idea de que el "talento" para la invención y la creatividad es un don natural más que algo dependiente de un sistema educativo; perspectiva ésta que ha sido otro de los lugares comunes de la difusión científica tal como ha aparecido en gran parte de la literatura de fines del siglo xIx e inicios del siglo xx. ${ }^{17}$ Pero, más relevante aun, el laboratorio confirma una construcción cibernética de la realidad, es decir, una dimensión cotidiana en donde individuos, máquinas y aparatos, interactúan de igual a igual; y, sobre todo, donde la eficacia de la comunicación y del saber está ligada a un aprendizaje acerca de cómo se aprende. ${ }^{18}$ En este sentido, la “invasión” a la ciudad puede entenderse como una invasión tecnológica, como algo que obliga a los individuos a cambiar radicalmente sus hábitos y, más que nada, a comenzar de cero. Con las imágenes de "transmisores de gran poder”, “receptores”, "tanques”, "nave aérea” y "glándula de terror”, la ciencia entonces es menos un saber que un sistema de aparatos, máquinas e instrumentos (EEG 111-27). De allí que, a lo largo de la narración,

\footnotetext{
${ }^{15}$ Véase por ejemplo Moreno Lupiáñez y Pont. Y también pueden consultarse Rhys Morus; Bensaude-Vincent; Bucchi; Gregory y Millar; Louw.

${ }^{16}$ No por casualidad es en el "altillo" de la casa donde se lo ha montado (EEG 85). En la versión original (EEO) este sitio de la casa es indicado como "buhardilla" (EEO 24) y el "laboratorio" como "buhardilla-taller” (EEO 34) y "taller-laboratorio" (EEO 51). De acuerdo con la narración allí se realizaba "astromodelismo", se trataba de "armar un microláser” y se "inventaban violines antiguos" (EEG 85-6).

${ }^{17}$ Véase por ejemplo Sánchez Ron. La idea del “genio” y, por ende, las perspectivas biográficas aún hoy dominan largamente la historia académica de la ciencia.

${ }^{18}$ Para una noción genérica de cibernética puede consultarse Wiener; von Foerster; y también de manera más específica Warrick.
} 
sea la posesión de estos elementos lo que otorga poder, eficacia y, en última instancia, victoria en términos bélicos. Tomamos, por ejemplo, el uso del lanzallamas en el enfrentamiento con los invasores (EEG 115-9). La ciencia es entonces, como decimos, tecnología, ya que posee un carácter claramente instrumental (EEG 119). El hecho de que todo enfrentamiento remita a un “detrás”, a alguien más que está detrás, favorece el ambiente de sospecha y conspiración. Se confirma este ambiente a partir del descubrimiento de que los hombres pueden ser convertidos en "hombres-robot" (EEG 125).

Lo que resulta realmente interesante en esto que podríamos señalar como realidad cibernética es que no existe una clara indicación acerca de la centralidad del poder, es decir, hay una indicación de que hay un "Ellos” que detentan todo el poder de la invasión a la tierra y el control de la tecnología, pero la verdad es que en la realidad cibernética todos son dominantes y dominados al mismo tiempo. ${ }^{19}$ La situación de los "hombresrobot", controlados por un aparato que se les inserta en la nuca o la de los "Mano", controlados por la "glándula del terror”, constituyen sólo dos ejemplos de esta realidad en donde los individuos -o "seres"- funcionan al mismo tiempo como autómatas pero también como entidades independientes. Este carácter difuso de la identidad y del poder es a nuestro modo de ver un anticipo del sistema de aparatos y objetos que en la actualidad se entiende como mundo.

La figura clave de esta noción de ciencia-tecnología y de estas actividades científicas es sin duda el personaje Favalli, que cumple con todos los requisitos y características del "científico". ${ }^{20}$ Pero es su situación de privilegio en la historieta lo que resulta más ilustrativo. Favalli es presentado como el representante de la "ciencia": su figura es asociada con la universidad en tanto símbolo de "saber" (EEG 93 y EEO 79); su especialidad es la "física atómica" que, como se sabe, a fines de los años cincuenta era una de las áreas consideradas de vanguardia del mundo científico (EEG 86); aparece en todos los momentos claves de la trama con un rol protagónico y especulativo -es él, por ejemplo, quien tiene la idea del “traje aislante” (EEG 92)-; incluso el mismo Breccia lo dibuja como un hombre maduro, con lentes y con un rostro que es mezcla de inquietud y certeza.

Además, en la propia historieta Favalli es indicado como trascendental: "No Fava, vos sos el más necesario" (EEG 96). Y, en este sentido, desde el mismo inicio, es quien posee un papel básico en contar “qué es lo que sucede”, es él quien descubre qué sucedía con la nieve, quien instala un grupo electrógeno en la casa o quien consigue los víveres y el automóvil (EEG 90, 97, 101). De manera tal que la construcción del sentido de realidad en la trama gira siempre en torno a esta idea de ciencia-tecnología que Favalli representa: "Fue Favalli, como siempre, quien nos volvió a la realidad” (EEO 154). Por ello es también quien siempre "teoriza” la situación (EEG 95 y EEO 50) y quien se convierte en "asesor

\footnotetext{
${ }^{19}$ Acerca del sentido de construcción de “lo real”, a partir de una perspectiva cibernética puede por ejemplo consultarse Dery Simon.

20 "Favalli, profesor de física atómica, no sabe mentir. Lo tengo de hijo" (EEG 86). E, incluso más relevante, en la versión original (EEO) se lee: "Reconforta tener al lado a un hombre como Favalli, de cerebro práctico, entrenado para resolver problemas técnicos. A eso, para él, se reducía el problema de nuestra supervivencia, a un problema técnico" (EEO 33); y también: "Realmente, era una suerte tener al lado a un hombre como Favalli, con él podríamos superar fácilmente todas las emergencias” (EEO 37).
} 
científico” del ejército de defensa (EEG 112). Es quien confirma que, si sentido alguno de realidad existe en El Eternauta, está ligado al sistema de artefactos y aparatos que, por medio de su empleo, utilidad o funcionalismo, construyen lo que sucede. Una vez más, la misma historieta lo certifica: “... pensaba en Favalli... Nos tiene en un puño, sabe más que todos nosotros juntos” (EEG 102), ${ }^{21}$ confirmando también de esta forma la confusión ya mencionada entre saber e información o, también, la idea de un saber enciclopédico; de manera tal que aparece como sinónimo de poder, de autoridad y por tanto como peligroso. Y esta autoridad del saber es ejercida de inmediato en cuanto Favalli comienza a teorizar también sobre política (EEG 106). ${ }^{22}$

Por otra parte, la dominante atmósfera bélica de la trama es entendida y enfrentada a partir de la ciencia-tecnología, de manera tal que, por ejemplo, los triunfos en los enfrentamientos son debidos a logros en el control y comando de la ciencia-tecnología; tomemos, por ejemplo, cuando ganan la batalla contra los invasores porque Favalli logró reutilizar el rayo láser (EEG 119). En EEO puede leerse: “Favalli, como buen científico, no miraba para atrás: sólo le interesaba la tarea que teníamos por delante: vencer al invasor.” (97). Y en este contexto Favalli es quien posee la mente y el ojo avizor: es quien siempre está descubriendo cosas o quien siempre está a la búsqueda de cosas diferentes, descubriendo, por ejemplo, que los “cascarudos” son en realidad robots dirigidos a distancia (EEG 119). El mismo héroe de la trama, Juan Salvo, un inventor a escala barrial que arma radios y después monta una fábrica de televisores, es presentado como una especie de Favalli en versión autóctona y libertaria (sería la versión “self-made man”, por decirlo de alguna manera).

Y precisamente, el papel relevante que los medios de comunicación-radio, televisión, transmisiones radiales- tienen en la trama se comprende porque, contrariamente a lo que sucede en la actualidad, por entonces eran asociados con una idea de tecnología, con un empleo vanguardista de la cientificidad. De manera tal que la confusión ya comentada entre ciencia y tecnología se asocia además con el malentendido entre información y saber.

\section{LA ATMÓSFERA CERO}

El Eternauta reduce Buenos Aires a escala planetaria y transforma su atmósfera en un medio ambivalente y escasamente seguro: el environment es inestable y la necesidad de adaptarse constantemente al medio-ambiente es una prioridad. La idea de libertad y de movilidad ya no se asocian ni se vinculan con un libre recorrido atmosférico sino, por el contrario, con la reducción de dichos recorridos a lo cerrado, a lo tecnológicamente previsible o posible, anticipando, curiosamente, el uso de esta idea en las discusiones de Baudrillard y Virilio en la actualidad (Virilio, La machine). Por ello también es que las

\footnotetext{
${ }^{21}$ Y también: “...cómo imaginaba derrotar a aquel ser de inteligencia superior...” (EEO 275). En este sentido, también, nada más real que Favalli.

${ }^{22}$ Es interesante comprobar cómo este discurso de Favalli es uno de los aspectos que, en la propia versión publicada por Gente y en versiones posteriores de El Eternauta, han sido modificados para ofrecer "mensajes" a los lectores y sugerir alegorías directas entre la historieta y una determinada situación política local. Acerca de estas variantes “políticas” del contenido en El Eternauta puede consultarse Morhain (37-79) y también Gociol y Rosemberg (462-3).
} 
distancias desaparecen y sólo pueden ser medidas en términos de traslados locales o saltos cronológicos. ${ }^{23}$ Guerras, plagas, invasiones, extensión indefinida del presente (EEG 100): la noción de variedad, de acumulación de sucesos y rápida evolución es sólo una apariencia. Lo que realmente sucede en El Eternauta es la detención, la instauración de una atmósfera cero, es decir, la ausencia de gravedad, la pérdida de peso de las cosas, la igualación de todos los reinos naturales (mineral, vegetal, animal), la desaparición de las escalas y de la proporciones y, más relevante aún, la permanencia de los signos y símbolos pero la evaporación de sus significados corrientes. ${ }^{24}$

Este aspecto de la atmósfera en El Eternauta se vincula sin duda con los más básicos principios de la cibernética y de la actividad científica tal como ha sido entendida luego de la invención de la mecánica cuántica. Menos que como una técnica estilística de la trama para acrecentar la idea de encierro, paranoia y persecución, el recurso a una cuestión atmosférica me parece una manera inteligente de hacer que todos los valores de los personajes sean sometidos a prueba. La atmósfera deja de ser una composición de gases y se convierte en un fluido, en éter -tal como "el aire" era entendido, aún en el siglo XIX, por autores como Dominique Fresnel (1788-1827)- donde todos estamos sumergidos. ${ }^{25}$ De manera tal que nuestra dependencia de dicho ambiente es mayor aún y la "nieve” que aparece en El Eternauta es tal vez el fenómeno atmosférico más determinante -el hecho de que la nieve no vaya acompañada de frío, que sea una nevada seca, constituye un dato significativo en este sentido, y como tal puede también ser asociada con la muerte: "Vacilé, la puerta, aunque no muy grande, me separaba hasta ahora de la muerte que reinaba afuera. Abrirla era sumergirme en medio de la nevada... en la muerte” (EEO 52).

Aquello que constituye un peligro, lo que mata, es en El Eternatuta algo transmitido por la atmósfera, sea porque viaja a través de ella, sea porque la usa como un instrumento. En este sentido resulta altamente significativa la mención a Daniel Defoe -“Por ahora somos robinsones. La casa es nuestra isla” (EEG 91)-, ya que la misma nos hace pensar en The Diary of the Year of the Plague (1722) y en el hecho de que, cuando existe una plaga, la atmósfera, el aire mismo, es el peor enemigo, como si aquello que nos hace distinguibles como humanos fuera lo mismo que nos debilita y expone a la muerte. ${ }^{26} \mathrm{La}$ atmósfera ya no nos protege: estamos expuestos a la realidad física de la Tierra en cuanto planeta.

Y encontramos aquí nuevamente una perspectiva cibernética: el hombre con prótesis tecnológica tiene más posibilidades de subsistir que el hombre primitivo y desnudo; toda edad del hombre es, en este sentido, una edad artificial, por lo que los parámetros

\footnotetext{
${ }^{23}$ Sobre esto último también puede consultarse Virilio.

${ }^{24}$ Estos eventos anticipan discusiones de la teoría cultural subsecuente. Sobre el particular pueden consultarse Baudrillard L'illusion; Haraway.

${ }^{25}$ Es interesante observar cómo la idea de inmersión está presente en el modo en que tanto Breccia como Solano López dibujaron los “trajes aislantes”. Si para Solano López (EEO) se parecían a un buzo marino, para Breccia (EEG) eran una mezcla de hombre-rana y astronauta.

${ }^{26}$ El mismo argumento, aunque de manera más sofisticada, es el que concibe Thomas Mann en Der Tod in Venedig. La idea de que "nos rodea la muerte” constantemente acecha a los personajes, sobre todo cuando se hallan en la casa-refugio de Vicente López. No por casualidad este mismo trabajo de Mann es citado en la historieta (EEG 100).
} 
establecidos de tiempo carecen de propósito y caen en desuso. El hombre ya nace a partir de la mediación tecnológica y pasa más tiempo con máquinas y aparatos que con otros individuos. El Eternatura se sitúa en este sentido en las antípodas del romanticismo filosófico y de la idea de un entendimiento intelectivo con la naturaleza: aquello que cuenta es el artificio y lo maquínico en sentido físico o imaginario. Toda noción sine die de naturaleza nos conduce al engaño y la desaparición.

EL VIAJE TECNOLÓGICO, LA PÉRDIDA DEL TIEMPO

Como ya mencionamos, en El Eternauta -al igual que en un gran número de las narraciones de ciencia ficción- los viajes constituyen en realidad exploraciones de lo cerrado, es decir, exploraciones de una serie de límites más allá de los cuales no se puede ir o el ir importa grandes riesgos. En este sentido, todos los viajes en El Eternauta constituyen viajes tecnológicos por cuanto su realización depende de aparatos, objetos artificiales o de un sistema basado en los mismos. La utilización de una "nave” para por accidente viajar en el tiempo constituye el clásico ejemplo sobresaliente de la historia (EEG 130). ${ }^{27}$ También como ya mencionamos, la situación temporal es tal que todo parece una prolongación o acotamiento de presente: la pregunta final del autor de historietas Oesterheld-“¿Será posible?”(EEG 132)-no es sino una confirmación de esta prolongación temporal. De hecho, el sitio al que Salvo viaja sin querer con la "máquina del tiempo" se llama “Continuum 4" (EEG 130). Este continuum es también aquello que permite asociar transcurso (devenir) con velocidad: “... los trajes es quizá lo único que nos ata al pasado... al pasado que apenas si es viejo de tres días... y que ya está una eternidad de lejos.” (EEO 211).

Con la pérdida del antes y el después como etapas irreversibles, el devenir se convierte en realidad en un continuum, en un presente constante. El viaje tecnológico es entonces un traslado en el espacio más que un movimiento en el tiempo y por ello las nociones básicas de objeto y materia desaparecen dando lugar a una ausencia de evidencia inmediata acerca de aquello que es real o imaginario. En este sentido, la inmaterialidad de lo que sucede cuando nos desplazamos en el espacio es algo que El Eternauta ya exhibía en sus páginas en la versión de1957. Resumiendo: la creciente "tecnologización” de nuestro entorno, en lugar de conducir a un sentido materialista de lo real, nos conduce hacia una pérdida de realidad de las cosas y de los objetos. El viaje tecnológico es el recorrido forzado de una paradoja por cuanto cuando más creemos estar en contacto con lo inmediato material, menos sentido de la realidad obtenemos. La ya mencionada pregunta final del historietista Oesterheld no es sino una constatación de ello (EEG 132). Más aun, la introducción de un personaje "historiador” acentúa aun más este rol del "historietista" (EEG 111). El historiador toma notas todo el tiempo, como si aquello que escribe fuese inmediatamente convertido en documento. Está además preocupado por la exactitud de lo que sucede (fechas, números, etc.) y constantemente pone nombres de

${ }^{27}$ Resulta interesante ver cómo el empleo del viaje en el tiempo -empleo del tiempo en sentido histórico- es inversamente proporcional en la trama al uso del tiempo entendido como inmediato, es decir, el tiempo en sentido horario o calendario. Cuanto más tiempo recorre El Eternauta en sentido histórico, de menos tiempo dispone en sentido horario. 
efemérides a lo que sucede, como lo que hace con el "Combate de la General Paz" (EEG 108, 120; EEO 120). El contraste sugerido entre el "historiador” y el "historietista” parece evidente: el historiador se fía de una serie de instrumentos y habita el tiempo narrativo, mientras que el historietista está más allá del tiempo narrativo y tiene una radical incertidumbre acerca del presente y de aquello que está sucediendo. Sostiene el historiador: "No se puede a la vez ser historiador y combatiente" (EEO 116). El historiador no puede afrontar el hecho, tan evidente para el "historietista" de la historia, de que la realidad no pasa ya por la dimensión material de nuestro mundo y de sus cosas. La asociación entre sistemas físicos estables y "mundo real”, que surgiera y se desarrollara en el siglo XIX gracias a la mecánica clásica y al naturalismo filosófico, llega entonces a su fin instrumental. El mundo real se hace invisible: éste es el verdadero desafío que El Eternauta-el personaje y la historieta- plantea.

NARRACIÓN Y FORMAS DEL PRESENTE. LA DERIVA BIOLÓGICA

En El Eternauta más que diálogos existe una narración en primera persona que alterna entre el propio Oesterheld -y la asociación entre el "guionista de historietas" de la trama y el autor es inevitable- y el personaje Juan Salvo. En El Eternauta -al igual que en Sherlock Time y Mort Zinder- un autor de historietas aparece en la narración y de esa manera obliga al lector a plantearse el género de aquello que está leyendo. En la indicada como segunda parte de El Eternauta, realizada por Solano López a partir de 1976 (EES), este autor aparece con el nombre propio de "Oesterheld” (EES 30). Esta narratividad se observa incluso en el estilo onomatopéyico elegido por Breccia: los ruidos no se escriben sino que se asumen como sobreentendidos, lo cual le resta dramatismo a la trama pero acrecienta la atención del lector en su contenido, en los eventos. Esta concentración extra en lo que sucede, típica por otra parte de la historieta de ciencia ficción, contribuye a la valoración del presente como centro de gravedad de la evolución y desarrollo de la trama. Este centro se establece con el hecho de que la trama transcurre constantemente en un mismo momento, es decir, que nada sucede si El Eternauta no está presente. El tiempo de la trama es el tiempo del personaje.

El presente en El Eternauta puede ser entendido como un presente narrativo o como un presente perceptivo/percibido de la narración. El presente narrativo a su vez se manifiesta a partir de un presente de enunciación o a partir de un presente de los enunciados. El presente perceptivo/percibido, por otra parte, aparece como un presente événementiel a partir de referencias a nombres y/o lugares o a partir de la radio. Si el presente narrativo nos invita a la metalectura y a salir imaginariamente de la trama hacia la historieta, por el contrario, el presente perceptivo/percibido nos fuerza al salto hacia delante, al paso de la historieta hacia la trama, a la búsqueda de una confirmación acerca de lo que estamos hablando, a la pregunta acerca de cuál será la siguiente cosa o de por qué ha sucedido lo que ha sucedido.

En cuanto al presente narrativo, existe una interacción entre el tiempo de enunciación y el tiempo de los enunciados que es aquello que hace que el presente sea el tiempo 
dominante o, mejor dicho, que se constituya en una deriva biológica (EEG 131). ${ }^{28}$ La noción de una deriva biológica obliga a concebir el pensamiento en relación con lo posible, de manera tal que localización, construcción de un sentido de lo real, establecimiento de un sistema de conceptos y relación de la experiencia con el pensamiento constituyen elementos fundamentales para comprender, no sólo lo que pasa, sino cómo lo que pasa sólo puede ser entendido a partir de cómo le pasa a la gente, y este suceder, además, como es evidente, no puede ser escindido de la situación biológica del individuo en cuestión. ${ }^{29}$

Pero también, la interacción entre el tiempo de enunciación y el tiempo de los enunciados, en el presente narrativo indicado, es aquello que refuerza la demanda de una especie de metalectura de la historieta. ${ }^{30}$ La leyenda y el culto en torno a El Eternauta, en tanto clásico del género historieta en el ámbito rioplatense (Morhain 111), se vinculan con esta posibilidad que, en 1957, constituía sin duda una perspectiva de vanguardia. A partir de esta técnica del manejo del presente, Oesterheld logra entonces no sólo establecer una trama determinada sino especular sobre cómo esta trama se convierte y se manifiesta en la historieta como género, y sobre cómo la categoría de presente puede situarse al centro de esta conversión.

Por otra parte, el presente perceptivo, el presente como surge percibido en la trama, nos remite a nombres y a lugares -“Rattin”, "Piazzola”, "Palito Ortega” y “Avenida Maipú” (EEG 86)- o a sucesos o eventos que surgen de la radio. La percepción del presente se halla así mediada por la familiaridad con lugares - un mapa, un territorio conocido (EEG 112)- o, más relevante aún, por las construcciones de los hechos que presentan los medios de comunicación; cuando éstos desaparecen o dejan de funcionar es justamente cuando se pierde el sentido de sociedad.$^{31}$ Esta situación es sin duda relevante para observar hasta qué punto la comprensión de lo que sucede está dada por eso que podríamos indicar como hecho tecnológico. ${ }^{32}$ No deja de ser interesante que todo vestigio de presencia humana, en gran parte de la trama, esté dado por la búsqueda de señales radiales (EEG 120). De manera tal que los aparatos -la tecnología en términos de EEG- aparecen como mediadores y conectores entre los individuos. En el mismo sentido los viajes, los movimientos y las posibilidades de supervivencia están ligados a hechos tecnológicos. Sostiene Favalli: "Sólo sobrevivirán los muy duros, los que sepan cuidarse... y venga ese traje yo saldré primero”; y también: “comida y remedios, son armas, no te olvides” (EEG 95, 97).

${ }^{28}$ Por otra parte, en la versión de Skorpio (EES) esta relación temporal se trastocará en fusión y el autor se convertirá no sólo en narrador sino también en personaje dentro de la historieta, con lo cual la relevancia de la deriva será más marcada aún.

${ }^{29}$ Para una explicación acerca de la idea de deriva biológica puede consultarse Maturana.

${ }^{30}$ Por ello es que nos parece lógica la evolución que las diversas versiones de El Eternauta han tenido y los cambios que las tramas presentan en este sentido. La situación extrema de El Eternauta II (EES), en donde el autor aparece como personaje de la trama y en donde los tiempos de la enunciación y de los enunciados se multiplican, era ya conjeturable en la misma versión inicial (EEO).

${ }^{31}$ Este aspecto se halla incluso más acentuado en la versión original (EEO), donde los sucesos públicos y la radio poseen no sólo una relación más estrecha sino que, al mismo tiempo, también ocupan un lugar preponderante en la trama (véase por ejemplo EEO 372-4, 375-7, 384-5 y 392).

${ }^{32}$ Lo que aquí también resulta interesante es que la gravedad de los hechos se halla representada, a partir de la radio, por la lectura de un comunicado (EEG 91). 
El presente es entonces en El Eternauta el tiempo por excelencia de la ciencia y la tecnología: sea porque la "ciencia” es entendida como saber informativo, sea porque la "tecnología” es asociada con la posesión de instrumentos o aparatos. El presente es el tiempo de El Eternauta por cuanto más que viajero es un viajero tecnológico o, mejor dicho, alguien que yerra siempre en torno a la misma temporalidad; la fusión del Salvo que llega del pasado con el Salvo del presente no es sino una metáfora de esta situación (EEG 131). Aquí El Eternauta es sin duda la reencarnación de la leyenda de Gilgamesh, el mítico héroe sumerio condenado a errar por la eternidad; es decir, más un prisionero de sí mismo que un liberador de otros.

El presente aparece entonces como una deriva biológica, es decir, como un devenir puro que sólo puede medirse en términos de percepción (experiencia sensible) o en parámetros de dimensión corpórea (decadencia, enfermedades, envejecimiento, etc.). La deriva biológica también significa, en términos individuales y cognitivos, ausencia de toda estructura estable, necesidad de localización y formulación “constructiva” de los conceptos. ${ }^{33}$ Por ello más que perderse en el tiempo, como sostienen algunos autores (Morhain 58), El Eternauta -y aquí me refiero tanto a la narración de Salvo como al presente de la enunciación que representa la narración del historietista- constata con desesperación la obsolescencia del tiempo mismo.

LA EXPLORACIÓN DEL ESPACIO Y DE LOS MEDIOS

Todo viaje en el tiempo es un recorrido circular, por ello en El Eternauta aquello que cuenta son los traslados en el espacio. En realidad no viajamos en el tiempo sino que nos movemos en el espacio, en diferentes dimensiones del espacio. La aeronave en la que viaja Juan Salvo es espacial (EEG 130). Lo cual nos lleva al asunto de la tecnología: si todo viaje es una mediación tecnológica, entonces toda percepción del espacio está signada por la tecnología. En este sentido El Eternauta es cibernética en estado puro por cuanto el entanglement entre hombres y máquinas, hombres y aparatos, alcanza una gran variedad de niveles, y no sólo con la situación obvia de los "hombres-robot”. Pero más aun, las explicaciones y el pensamiento sólo pueden ser entendidos de manera local, a partir de la deriva propia de cada uno y, sobre todo, sólo entendiendo cómo entendemos podemos llegar a una cierta comprensión; esto también es parte de la dimensión cibernética mencionada. ${ }^{34}$ Por ello lo que resulta interesante en El Eternauta no es sólo el anclaje local de la historieta sino el hecho, característico a nuestro modo de ver de lo que podríamos indicar como la cultura rioplatense, ${ }^{35}$ de que sólo puede haber comprensión cuando se comprende qué es comprender o, cuanto menos, cuando se teoriza dicha situación como parte de una expectativa hacia el porvenir o, más relevante aun, hacia aquello que se considera como posible.

Y, bajo estas condiciones, percepción del espacio significa también introducirse en el dominio de los medios de comunicación: aprehender el espacio es, en gran número de

\footnotetext{
${ }^{33}$ Véanse por ejemplo Piaget; Maturana.

${ }^{34}$ Acerca de esta dimensión de la cibernética puede consultarse Foerster Understanding.

${ }^{35}$ Sobre el particular puede consultarse Canaparo Muerte.
} 
ocasiones, aprehender a partir de los medios de comunicación. Por ello, desde el inicio mismo de la trama, cuando los personajes quieren "saber lo que pasa”, tratan de enterarse a partir de la radio (EEG 91). El mismo éter al que hacíamos referencia como una amenaza constante en términos atmosféricos es también el que vehiculiza los mensajes, las ondas, la información, las señales y los signos, y he aquí la cuestión innovadora: los medios de comunicación también transportan señales y signos, su realidad de alguna manera también es visual. ${ }^{36} \mathrm{Y}$ es que esta dimensión mediática se acopla a las características mismas del éter: el éter es inmóvil, es un espacio absoluto en sentido físico, constituye el espacio. En El Eternauta, como decimos, aquello mismo que vehiculiza la muerte hace posible la transmisión de mensajes y, sobre todo, la construcción de una comprehensión acerca de lo que pasa.

Y es así, a partir de esta condición mediática del espacio, que comprendemos que el mundo de El Eternauta -e indudablemente el nuestro- es irreversiblemente tecnológico. No tanto porque los media sean en sí un fenómeno tecnológico, sino, si seguimos a Baudrillard, por cuanto ellos introducen una lógica y un timing en la percepción y el pensamiento de los individuos del cual no se regresa. El Eternauta es menos la saga heroica de un individuo o la alegoría de una situación administrativa del Estado, que la figuración de una condición de la cultura y del mundo contemporáneos. ${ }^{37}$

El Eternauta es una brillante premonición del porvenir que es nuestro presente entendido como devenir: cuanto más tecnológicamente evolucionamos, menos movilidad poseemos. Cuanto más depende nuestra imaginación de instrumentos y aparatos -porque los emplea, porque los recorre o porque los incorpora- menos seguros estamos de nuestro sentido de realidad. Y por ello, siendo una premonición, construyendo en gran medida nuestro horizonte de espera, ${ }^{38}$ El Eternauta ha contribuido a determinar nuestro futuro mismo o, cuando menos, la relación del presente (devenir) con aquello que entendemos como futuro (lo aún por venir). Y es por ello que, el presente de la trama, el presente de la enunciación de la trama, el presente en que la historieta fue editada y nuestro presente actual parecieran ser la misma cosa: como El Eternauta, aunque por razones diversas, estamos viviendo un éloignement sin precedentes del devenir en cuanto sinónimo de actualidad.

\section{BiBliografía}

Baudrillard, Jean. Le système des objets. París: Gallimard, 1968. L’illusion de la fin ou la grève des événements. París: Galilée, 1992.

Bensaude-Vincent, Bernardette. L'opinion publique et la science. París: Institute d'édition, 2000.

Bourdieu, Pierre. Les regles de l'Art. París: Minuit/Seuil, 1992.

Bucchi, Massimiano. La scienza in pubblico. Milán: McGraw-Hill, 2000.

Canaparo, Claudio. Ciencia y escritura. Buenos Aires: Zibaldone, 2004.

${ }^{36}$ Sobre este aspecto -y en relación con una idea tradicional de "sociedad"- puede consultarse por ejemplo Jameson.

${ }^{37}$ Sobre la noción de “figuración” véanse por ejemplo Lyotard; Fahnestock.

${ }^{38}$ Acerca de la noción de horizon d'attente pueden consultarse Ricoeur; Koselleck. 
Muerte y transfiguración de la cultura rioplatense. Buenos Aires: Zibaldone, 2005.

Cantor, Geoffrey et al., eds. Science in the Nineteenth-Century Periodical: Reading the Magazine of Nature. Cambridge: Cambridge UP, 2004.

y Rally Shuttelworth, eds. Science Serialized: Representations of the Sciences in Nineteenth-Century Periodicals. Cambridge: MIT Press, 2004.

Dery, Mark. Escape Velocity: Ciberculture and the End of the Century. Nueva York: Grov Press, 1996.

ed. Flame Wars. The Discourse of Ciberculture. Durham: Duke UP, 1994.

Deleuze, Gilles. Critique et clinique. París: Minuit, 1993.

y Felix Guattari. Kafka : pour une littérature mineure. París: Minuit, 1975.

De Santis, Pablo. La historieta en la edad de la razón. Buenos Aires: Paidós, 1998.

Fahnestock, Jeanne. Rhetorical Figures in Science. Nueva York: Oxford UP, 1999.

Fontanille, Jacques. Sémiotique du visible. París: PUF, 1995.

Floch, Jean-Marie. Identités visuelles. París: PUF, 1995.

Foerster, Heinz von. Cybernetics of Cybernetics. Minneapolis: Future Systems Inc., 1995. Understanding Understanding. Essays on Cybernetics and Cognition. Nueva York: Springer, 2003.

Foster, David William. From Mafalda to los Supermachos. Latin American Graphic Humour as Popular Culture. Boulder: Lynner Rienner, 1989.

Genette, Gérard. Seuils. París: Seuil, 1987.

Glasersfeld, Ernst von. Radical Constructivism. Londres: Falmer Press, 1995.

Gociol, Judith y Diego Rosemberg. La historieta argentina. Una historia. Buenos Aires: De la Flor, 2000.

Goimard, Jacques. Critique de la science-fiction. París: Pocket, 2002.

Gregory, Jane y Steve Miller. Science in Public: Communication, Culture, Credibility. Cambridge: Perseus, 1998.

Habermas, Jürgen. La technique et la science comme “idéologie”. París: Gallimard, 1973. Haraway, Donna. Simians, Cyborgs, and Women. The Reinvention of Nature. Londres: FAB, 1991.

Heisenberg, Werner. Lo sfondo filosofico della fisica moderna. Palermo: Sellerio, 1999. HGO. Victor Bailo y Daniel Stefanello, dir. Buenos Aires: 1998.

Jameson, Frederic. The Geopolitical Aesthetic. Cinema and Space in the World System. Londres: BFI / Indiana UP, 1992.

Jasanoff, Sheila et al., eds. Handbook of Science and Technology Studies. Thousand Oaks: Sage, 1995.

Koselleck, Reinhart. Futuro passato. Roma: Marietti, 1986.

Louw, Eric. The Media and the Cultural Production. Londres: Sage, 2001.

Lyotard, Jean-François. Discours, figure. París: Klincksieck, 1971.

Mann, Thomas. Der Tod in Venedig. Berlín: S. Fisher, 1913.

Masotta, Oscar. La historieta en el mundo moderno. Buenos Aires: Paidós, 1970.

Maturana, Humberto. La realidad: ¿objetiva o construida? I. Fundamentos biológicos de la realidad. Barcelona: Anthropos / Iberoamericana, 1995. 
La realidad: ¿objetiva o construida? II. Fundamentos biológicos del conocimiento. Barcelona: Anthropos/Iberoamericana, 1996.

McLuhan, Marshall. Understanding Media: The Extensions of Man. Londres: ARK, 1987.

Moreno Lupiáñez, Manuel y Jordi José Pont. De King Kong a Einstein: la física en la ciencia ficción. Barcelona : Edicions UPC, 1999.

Morhain, Jorge Claudio. La Argentina premonitoria en El Eternauta de Héctor Germán Oesterheld. Buenos Aires: Axxón 96, 1998.

Muñoz, Pablo. “Un poco de historia”. Oesterheld y Solano López. El Eternauta. Buenos Aires: Biblioteca Clarín de la Historieta, 2004. 14-18.

Oesterheld, Héctor. El Eternauta y otros cuentos de ciencia ficción. Buenos Aires: Colihue, 1996. (Indicado en el trabajo como EEN).

El Eternauta y otras historias. Buenos Aires: Colihue, 1998. (Indicado en el trabajo como EEG).

Oesterheld, Héctor y Francisco Solano López. El Eternauta. Buenos Aires: Biblioteca Clarín de la Historieta, 2004. (Indicado en el trabajo como EEO).

El Eternauta II. Buenos Aires: Biblioteca Clarín de la Historieta, 2004. (Indicado en el trabajo como EES).

Ortega y Gasset, José. Ensimismamiento y alteración. Meditación de la técnica. Buenos Aires: Espasa-Calpe, 1939.

Piaget, Jean. L'epistémologie génétique. París: PUF, 1970.

Rhys Morus, Iwan. Frankenstein's Children. Princeton: Princeton UP, 1998.

Ricoeur, Paul. Temps et récit. París: Seuil, 1983-1985.

Rivera, Jorge. Panorama de la historieta en la Argentina. Buenos Aires: Libros del Quirquincho, 1992.

Sánchez Ron, José Manuel. El siglo de la ciencia. Madrid: Taurus, 2000.

Sasturain, Juan. El domicilio de la aventura. Buenos Aires: Colihue, 1995.

Simon, Herbert. The Sciences of the Artificial. Cambridge: MIT Press, 1981.

Stengers, Isabelle. Cósmopolitiques. Mécanique quantique: la fin du rêve. París: La Découverte, 1997.

Trillo, Carlos y Guillermo Saccomanno. Historia de la historieta en Argentina. Buenos Aires: Record, 1980

Virilio, Paul. La machine de vision. París: Galilée, 1988. Esthétique de disparition. Paris: Galilée, 1989.

Warrick, Patricia. The Cybernetic Imagination in Science Fiction. Cambridge: MIT Press, 1980.

Wiener, Norbert. Cybernetics or Control and Communication in the Animal and the Machine. Cambridge: MIT Press, 1961. 